\title{
Health Maintenance by Balanced Psyche, Spiritual Life, Hygiene, Endoecology and Ecological Nature
}

\author{
Evgeniy Bryndin ${ }^{1 *}$ and Irina Bryndina ${ }^{2}$ \\ ${ }^{1}$ Research center "NATURE INFORMATIC", Russia \\ ${ }^{2}$ Technological platform "FUTURE MEDICINE", Russia
}

*Corresponding author: Evgeniy Bryndin, Research Centre "NATURE INFORMATIC", Technological Platform Future Medicine, Novosibirsk, Russia

\begin{abstract}
Purity of the person is guarantee of his health. Spiritual and also mental (sincere), power, physiological and anatomic purity is criterion of health of each person. The hygiene maintains anatomic health. The endoecology maintains physiological health. The natural ecology and physical culture provide power purity. The orthodox psychology helps to provide mental purity. Spiritual life provides spiritual purity. The hygiene and endoecology, physical culture and natural ecology, balanced mentality (quiet mind and quiet heart) and spiritual life are a healthy lifestyle. The healthy lifestyle maintains purity and a healthy condition of the person.
\end{abstract}

Keywords: Hygiene; Endoecology; Natural ecology; Balanced mentality; Spiritual life; Healthy lifestyle

\section{Introduction}

Definition of health by World Health Organization: Health is a condition of full physical, mental and social well-being. Definition of health in the law on health protection: Health is a condition of physical, mental and social wellbeing at which there are no diseases, and disorders of functions of bodies and systems of an organism. The medical reference book describes symptoms more than one thousand diseases. To carry out periodically diagnostics on all possible diseases and frustration of bodies and systems of an organism for all population it is almost impossible, and, therefore, to hold preventive events. The genetic passport of health indicates predisposition to various diseases, as hereditary conditionality under adverse environmental conditions. The word HEALTH in the name of the genetic passport has donozological character. The genetic passport indicates predisposition to various diseases. It is the donozological passport. Predisposition to diseases demands from the person of constant attention to environmental conditions and to control of the relevant vital systems which are inclined to these diseases under adverse environmental conditions. Based on the genetic passport the complex of preventive and diagnostic actions for prevention of developing of a disease is formed. Health category not only medicobiological, but also social. Performance by the individual of the biological and social functions can be treated as manifestation of health. Ability of the individual to realize the biological and social functions indicates his health. Not ability to show the health - in other words to realize the biological and social functions - indicates a disease or an illness of the person.

\section{Hygiene of External Purity of an Organism}

\section{Care of Skin}

Skin constantly becomes soiled. On its surface skin fat, sweat, the disappearing scales of a horn layer, dust accumulate; all this mixes up and turns into dirt. Dirt causes the naggers, and it conducts to raschesa and appearance of pustulous diseases of skin. Violation of integrity of an integument can be caused also by other reasons - touch to the heated objects, excessive influence of sunshine or cold, impact on skin of alkalis or acids, can be a consequence of a bruise, blow, etc. The main thing in care of skin - maintenance of its purity and maintaining integrity and acid-base balance. The human health, its working capacity, resilience to various diseases depends on a condition of an integument. Skin represents the difficult and important member of the body performing many functions: protection of the internal environment of an organism, allocation from an organism of products of a metabolism, thermoregulation, etc. In skin there is many the nervous terminations and therefore it provides constant information of an organism on all irritants operating on a body. It is counted that on 1 , the $\mathrm{cm}^{2}$ of a surface of a body is necessary about 100 painful, 12 - 15 colds, 1 - 2 thermal and about 25 points perceiving atmospheric pressure. 
All these functions are performed in full only by healthy, strong, pure leather. The impurity of skin, skin diseases weaken its activity that negatively affects the state of health of the person. Basis of care of skin - regular washing of a body hot water with soap and a bast. It is carried out at least once in 4 - 5 days in soul, a bathtub or a bath. It is obligatory to change underwear after that. Care of skin of hands requires special attention as on it pathogenic microbes and eggs of helminths which then will be postponed for food and ware can get. Especially there are a lot of microbes (about 95\%) which are on skin of brushes, accumulates under nails. After a toilet, performance of various works and before food it is necessary to wash hands with soap. Hands it is necessary before going to bed, in the morning after rise. At least once a week it is necessary to cut shortly nails that under them dirt did not accumulate. The bacteria and fungi causing infectious diseases get into skin at violation of its integrity. When receiving small wounds, the damaged places need to be greased with iodine tincture.

\section{Care of Hair}

In skin of a hairy part of the head, as well as in face skin, there is a lot of grease and sweat glands. The horny cells of epidermis disappearing in the form of scales and the dust which got on skin from air mix up with then and skin fat which at non-compliance with rules of care of hair decays that leads to emergence of an unpleasant smell from hair; hair at the same time become grease, brilliant. It is necessary to wash the head at least once a week. After washing hair should be dried a clean towel and to comb. It is better to use a rare crest for hair, without sharp teeth not to scratch head skin; it is not necessary to use others hairbrush. Care of hair provides a timely hairstyle and washing. It is inadmissible to use the laundry soap or synthetic detergents intended for washing of linen for washing of hair. It is recommended to use toilet soap or shampoo. At appearance of dandruff an oily hair of 1 - 2 time a month can be washed with shampoos.

\section{Care of Teeth}

In the absence of due care of teeth and an oral cavity under the influence of microbes there is a decomposition of the remains of the food which got stuck between teeth; at the same time various acids which lead to damage of tooth enamel are formed. On it there are dot dark stains, and gradually going deep defects are formed eventually - caries develops. In the absence of treatment, the pulp located in tooth is involved in process. Inflammation of a pulp is followed by sharp pains. If in due time not to take measures, there is a pulp necrosis that leads to full loss of tooth. In the absence of daily care of teeth the so-called scale is postponed. It is necessary to brush teeth not less once a day. Completely to remove the remains of food and the raid which is formed on teeth and gums in a night when toothbrushing it is necessary to drive a brush in the horizontal and vertical directions on the external and internal surfaces of teeth. The brush needs to be kept clean. For removal of the remains of food it is necessary several times during the day, to rinse after each meal a mouth of clear water. Systematic care of an oral cavity and teeth - one of mandatory hygienic requirements. Through an oral cavity and because of decayed teeth pathogenic microorganisms get into an organism. In the morning, before going to bed and after each meal it is necessary to brush carefully within 2 - 3 min. teeth paste, as from external, and from the inside. The toothbrush needs to be directed from gums to teeth, and not vice versa and only vertically. At mealtime it is desirable to avoid fast alternation of hot and cold dishes.

\section{Care of Legs}

The main thing here - continuous care of the maintenance of legs in purity. In skin of a sole of legs and palms there is many sweat glands in comparison with other parts of the body therefore on skin of legs sweating plentiful. The emitted sweat mixes up with dust owing to what legs become soiled. At bad care of legs on them an intertrigo, cracks pleated between fingers can be formed that creates prerequisites for appearance of pustulous and fungal diseases. Occupations barefoot, perspiration promote emergence of scrapes, local inflammatory processes and callosities. That is why it is necessary to wash daily legs with soap, to change socks more often. Dry callosities should be deleted in due time by means of pumice, a corn plaster. The correct adjustment and observance of rules of wearing footwear are of great importance. Purpose of footwear consists in protection of the legs against dampness, cold, against influence heated by the sun of paving against mechanical damages. Footwear has to meet certain fiziologo-hygienic requirements: it is good to absorb and carry out outside sweat, to have small heat conductivity, not to lose the properties when drying.

Footwear has to correspond to a form and the sizes of a leg, i.e. to be correctly adjusted; behind footwear leaving is required. At correctly adjusted footwear the leg should not be under pressure anywhere, and big and second fingers should not rest against part of sock of footwear. Between toes and edge of footwear there has to be a gap which can be determined by pressing from the outer side of a sock. In order that footwear kept the hygienic properties, permanent care of it and careful attitude to it is necessary. It is necessary to remember that crude, not dry-through leather boots lose the heat-shielding properties. Dirt and excess of shoe cream also worsen quality of footwear. Wet and dirty footwear should be cleaned first from dirt and to dry up. Footwear needs to be dried evenly and gradually; at fast drying its hygienic properties worsen. Shoe cream should be applied on the dried-up footwear with a uniform thin layer and to pound dry as the excess of cream reduces air permeability and porosity of material of which footwear is made, than its hygienic properties decrease.

\section{Choice of Clothes}

The clothes protect an organism from adverse effects of the external environment, mechanical damages and pollution. From the hygienic point of view, she has to help to adapt to various environmental conditions, to promote creation of a necessary microclimate, to be easy and convenient. Heat-shielding properties of clothes, its air permeability, naturalness matter. At exercises on the street in the summer the form can consist of an undershirt, short and also a cotton or woolen knitted suit. During the occupations in the winter on the street sportswear with high heat-shielding and 
wind-shelter properties is used. Usually this cotton linen, a woolen suit or a sweater with trousers, a hat. At strong wind the windshelter jacket from above is put on. Different types of sportswear from synthetic fabrics are recommended to be applied only to protection against wind, a rain, snow, etc. It is unhygienic to use sportswear in everyday life. Footwear has to be easy, elastic and well ventilated. It is necessary that its heat-shielding and waterproof properties corresponded to weather conditions. Best of all the footwear from genuine leather having small heat conductivity, good elasticity and durability and also having ability to keep a form after soaking meets these requirements.

\section{Endoecology of Purity of The Internal Environment of An Organism}

The endoecology is the methods and means allowing to maintain purity of the internal environment of an organism thereby providing normal activity of all bodies and fabrics. Purity of the internal environment of an organism is a basis of bases of its normal activity. The person - an integral part of the nature therefore each cage of our organism sensitively reacts to any changes of state of environment. The biochemical processes proceeding in living cells of which all consists live on our planet including the person, were created long ago, millions of years ago. And all these millions of years evolution of the live world happened in ideal conditions of primitive ecological purity. But in the 20th century technical progress to unrecognizability changed the image of our planet. For the last decades we is imperceptible for itself kind of became inhabitants of other planet. Unfortunately, most of us lives in the distance from untouched corners of the nature, in an environment of numerous chemicals, the toxins getting to an organism with food, water, air to which we breathe. Chemicals break work of the immune system, contributing to the development of allergic diseases, immunodeficiencies, oncological processes. More than $80 \%$ of toxins accumulate in intercellular space-a lymph. And in this environment, there are also all our cages, and the polluted space has the most negative impact on them. At indispositions, first of all, it is necessary to pay attention to work of lymphatic system. She makes cleaning of "garbage" - is responsible for a conclusion of toxins from an organism. She throws out through the capillary's slags directly in intestines, and then outside. And it is natural, from that, lymphatic system how well works, also purity of the internal environment of an organism and consequently our health and health depend. Very well stimulate work of lymphatic system cowberry - it cleans walls of vessels, parsley strengthens a lymphatic drainage of bodies and fabrics, blackcurrant favorably influences a liver and provides antirheumatic action. Also, excellent limfostimulyator are the melissa, a dogrose brown. Traditional medicine for clarification of a lymph recommends to drink horseradish infusion on water in the ratio 1:1 (on a teaspoon three times a day) or within one day in each hour to accept a little juice, prepared from carrots, beet and a cucumber (a ratio 6:1:3). Besides, advise all who show consideration for a condition of the organism there are a sea cabbage salad and Russian cabbage soup from young leaves of a nettle more often.
The good procedure is clarification of an organism in a bath or a sauna. Heat dissolves fats and opens a time, and thus together with then harmful substances and excess of liquid are removed from an organism. By the way, for this reason many women notice that regularly visiting a sauna, begin to grow thin quickly. It is very useful to carry out lymphatic drainage massage to time of visit of a bath. It is for this purpose recommended to rub 10-15 times a body a rigid brush or a bast: from below up and outside inside - in pelvic, belly and chest areas and also on legs and hands; from top to down and behind forward - on the head and a neck. These movements correspond to the direction of a lymph flow and by that stimulate work of lymphatic system. Today all know, the good ecology is how important for human health. And if not always in our forces to take care of improvement of ecological space around, then the ecology in our organism depends only on ourselves. To normalize the mechanism of cellular updating (regeneration) it is necessary to customize daily vital systems and complete functioning of an organism at the spiritual, power, physiological and anatomic levels, according to the vibration field nature of life and self-organization of biosystems of the person through a biofield.

\section{Vibration Field Nature of Life}

Everything that exists, vibrates. The matter is slowly vibrating energy. The spirit, thought, idea - is the energy vibrating with the highest speed. All types of life show fluctuations, frequencies and which amplitudes various. According to spiritual truth of creation of life, God in 6000 years created power information vibration fields and, on their basis, generated life. According to the physical theory of explosion, there were power information vibration fields from which by self-organization there was a life. The latest discoveries of modern physics confirm this fact. Life is a perpetual motion. In the Universe nothing can stop. Distinctions in manifestation of a matter and energy are explained by that they variously vibrate. According to definition of modern physics, vibration or fluctuation are processes of radiation of energy through identical periods. Fluctuation is a fundamental form of the movement. The perception of a sound requires a certain frequency of fluctuation, for light higher speed of fluctuation of energy. Then energy is more perfect - that with greater speed it vibrates. Any vibration has property to extend and have impact on environment. It is possible to present, what changes in the space surrounding us and in us cause vibrations of anger, hatred, rage, and what vibration changes are caused by fine music, the feeling of love shown by us or to us. From the highest spiritual spheres of vibration of spirit and thought consistently astral worlds, and then physical get, recovering them and extending in all the Divine Providence. Any matter (dense low-frequency energy) interacts with high-frequency energiya and generates information (shows consciousness). Beginning from the elementary cage and to space structure, for example stars, everything is absolute in the universe contains energy and generates information (shows consciousness). The energy which is in everything is radiated from everything in the form of vibrations, radiations. Everything in the Universe radiates round itself power vibrations. Vibrations differ on frequency. The consciousness is more shown, the energy is 
stronger and the more so highly this energy vibrates. That is, then the consciousness in the person is shown above, especially, strong highly vibration energy is radiated by this person. The person who reached high spiritual development, radiates very thin vibrations. At its presence it is comfortable. Its vibrations very strongly energetically feed. For this reason the highest energy of love is called as divine love.Beginning from corpuscles, electrons, atoms, smaller particles of energy not known to science, to the worlds, solar systems, galaxies so far, everything is absolute in the Universe is in a condition of fluctuation, perpetual motion. All material forms of the nature differ from each other in a vibration condition of energy.

We will present the Universal scale of power vibrations, that is a life scale, on extent of manifestation of energy and frequency of vibrations. On one limit pole - inner worlds, energy forming them, show the highest vibrations and the highest consciousness, and come nearer to the Absolute. Here vibrations of energy happen to such intensity and to such speed limit that are represented being at rest. On other, opposite end of a scale there are dense forms of a material world (stone) which vibrations are so low, slowed so down that too seem motionless, though it not so. Between them the huge range of vibration life, huge range of the shown consciousness. Everything in the universe moves, everything vibrates, nothing is based, the stop means disappearance in the universe. Everything vibrates variously and in various directions. From extent of vibration, extent of manifestation of life depends. The vibration of energy which contains in a form is higher, this form will be more vital. Both the stone and fiery elements vibrate, both the live. The fiery elements are more vigorous. Different manifestation of vibrations - different manifestations of life. With change of speed of vibrations manifestation of life and manifestation of consciousness changes. The frequency of vibrations is higher, the life is shown more actively, and the consciousness is higher. In the Universe there is an infinite set of forms of life, a set of the forms of existence differing on the level of consciousness and level of energy. The person is identical to the Universe, we are triple, as well as the Universe. We have a physical body which vibrates. The radio body shows higher vibrations and it more power saturated, than a physical body. The radio double who supplies it with energy has each body. Higher body, a body thin or astral - vibrations thinner, energy mightier and strong. The consciousness of this body is shown as feeling. The thinnest on vibrations is the mental body. We are the feeling and conceiving beings therefore constantly we radiate these or those vibrations of feelings and thoughts in environment. The world around very much depends on our impact on it. Flowers if we often are at rest, pleasure or love can blossom. Relatives if we often are in a condition of anger, irritations, rage can be ill. The disease is the low frequency destroying vibrations. To change the vibrations, change the state. To change the destroying vibrations, it is necessary to concentrate on positive thoughts, desires and feelings. To contact with the astral world means that your astral body has to vibrate in the range of frequencies, as the astral world. It is reached by creative occupations at people of art, at poets, musicians, artists. Depending on that with what plan of the astral world his astral body enters a resonance, there are these or those works of art. If there is a resonant accord with high plans of the astral world, its art transfers vibrations of this plan. The person of art is only the conductor of influence of vibrations of the highest worlds on the terrestrial world. If more often it is adjusted on vibration of the lowest subplans of the astral world, there is Bosch's painting. Remember two different in influence on the viewer of pictures Chagall. One pictures when it was in love, and then his astral body vibrated in unison with the highest plans of the thin world since radiated very high vibrations of love. And others, gloomy, disturbing, sated in the brown flowers when he endured arrival of fascism.

A condition of alarm, fear are conditions of low vibrations. His astral body could be adjusted only on vibration of low subplans of the astral world. From here such colors in pictures and such impact on the viewer. On influence on us of pictures, music, poetry, we can always define, in what emotional states there was their founder. The most power, the most effective is the thought. The thinnest on vibrations is our mental body. Thought the strongest, most effective manifestation of consciousness which is available to the person. The person with a spiritual mental body is spiritually imperious, mighty being. We exist at the ocean of vibrations. Everything vibrates around, any space vibrates. We catch any vibration background, having entered the apartment, establishment, communicating with any person, being outdoors. Everything is absolute in the world bears information on itself since all vibrates. Unfortunately, we, ordinary people, are capable to feel very small range of vibrations. Spiritual development is an ability to feel more highly frequency range of vibrations of the world in which we exist. For us the most important are states of mind and ability to control the emotions and the thoughts.

Any state of mind is the vibration radiation therefore it is necessary to trace the states of mind and if it is necessary to change the sincere manifestations consciously. To transfer itself or other person to a kind state of mind it is possible to use highly vibrating music, it is that tool which influences our state of mind. It is better to form spiritual consciousness which constantly holds a kind state of mind. The government, which is anxious with development of the people, has to pay more attention to development of art and spiritual culture, and not just to development of the industry. High art and culture spiritualize and improve and raise a power state. The correct prayer as expression of love for God, as gratitude for life, is a power method of management of a power state, method of an eminence of a state of mind. It is possible to lower the vibration state, to enter the person into a condition of anger, art it too can do. The martial music adjusts the person on eagerness to fight and aggression. Metal music causes aggression in youth. At communication with the person angry, angry other person experiences vibration influence and too starts being irritated. It is possible to catch not only an infection; it is possible to catch low vibrations for this reason don't allow at the presence of low manifestations. The person radiating low energy is a destruction source, it is really dangerous. 
Everything that is near it, with is adjusted with its vibration. Notice that near the angry person involuntarily you become itself angry. Involuntarily each person enters a resonance with stronger vibration. Therefore, well influences the world around of people radiating high vibrations. It too adjusts people around, but does them more friendly, quiet, peaceful. The intensive radiator of lowfrequency energy is the dangerous destroyer of world around. The person with high-frequency vibration harmonizes environment. Near it sincerely quietly, comfortably, people unconsciously seek to be near it. Such person involuntarily inspires love as possesses huge attractive force. It spiritualizes and raises a vibration condition of the environment. Low states of mind show low vibration. Such states of mind as rage, hatred, irritation is very low vibrations. The highest state of mind on vibrations, so on energy the strongest is a condition of love. The thinnest state - a condition of love. It is pleasant to us to communicate with the person who loves us. Vibrations which are radiated by this person very high, means the very strong. Contact with the person loving us is a most powerful power feed. The best power protection is a condition of love.

There is nothing in the Universe that wouldn't radiate energy of various frequencies. Each blade, each tree, each living being belonging to a kingdom of plants in our nature radiates energy. Similarly, with fauna. All living beings of this world too radiate various on energy vibrations. The person constantly radiates energy in world around. His physical body, his astral body and a mental body radiates energy. The energy radiated by each person corresponds to the level of its development, corresponds to its emotional and mental condition. Each person possesses the vibration passport, much more essential, than the legal document. It precisely characterizes the level of its development. This quality of vibrations which it radiates. If near the person it is disturbing, there is a desire quicker to leave it, it occurs because the person radiates low vibrations. Its level of consciousness is still very low. It is necessary to learn to perceive the world appreciably, that is to perceive vibration radiations of all in world around. For this purpose, it is necessary to restore and develop a feeling-knowledge. When we think, we show these or those emotions, feelings, states, we radiate energy, various vibration states. Knowing it, and that our vibrations have impact on people around, it is necessary to learn to control the positive creating vibrations. The person influences the vibrations the nature, people, the dwelling, the city, Space. Everything in the world bears information on itself. These are vibrations. We now exist at that level of development when we think that verbal information is more important. Verbal information is only data. Very often false. The modern person is capable to feel very big range of vibrations of environment, people, animals, plants, stones, rooms, etc.

The person knows about it or not, he always reacts to vibrations which perceives. Any person should react to vibrations of world around. All of us inevitably perceive and we react to vibration influence of environment. We are shipped by living conditions in the ocean of the energy influencing our feelings, a state of health, a thinking orientation. So, spiritual development is a development of ability to feel wider range of vibration influence of world around. Then more, the person is spiritually developed, especially he is capable to apprehend high vibrations. And the more so high vibrations are radiated by him. The less, the person is spiritually developed, the less he is capable to perceive vibrations of world around, he is capable to perceive only low vibrations. Also radiates too only such. So, nothing is based, everything moves, everything vibrates. The Universe moves on the basis of two vibration principles - the movements circular and oscillatory. In the universe everything moves around and fluctuates. Planets move around, all solar system moves around. The Universe makes two types of the movement: circular and oscillatory. Activity of the person proceeds around and fluctuates. Sincere and mental manifestations of the person exist according to these principles, including. Each person radiates energy when thinks or feels. Sincere and thought processes at women and men happen differently. That is why two women well understand each other, but the woman and the man difficult understand each other. The principle of thinking at them various. The principle of thinking at women irrational associative, that is circular. Thinking of men - rational oscillatory. A feelingknowledge at women too are longer, flowing, mutually influencing. Men feel much less, sincere processes proceed quicker.

So, all our thoughts, emotions, states are no other than manifestation of astral and mental bodies and manifestation of their energy of various vibrations. With spiritual development of the person not only the range of the energy radiated by it extends, not only manifestation of consciousness of his body's changes, but also there is an ability to control and change the vibrations. But it is always necessary to remember that we exist at the ocean of vibrations that radiates energy everything absolutely and everything influences us. Any person should react to vibrations of world around. All of us are simply doomed to perceive and react to vibration influence of environment, to control positive creative vibrations.

\section{Person as Object of Research}

Development of an organism goes under the influence of mental energy. Mental energy gets into all cages. The biochemical carrier of mental energy are structural components of a cover of nervous fibers of the lipidic nature. Mental energy influences an electromagnetic homeostasis. Quality of mental energy depends on consciousness, feelings and desires. Arriving justly on conscience, the person produces mental energy of tranquility, which provides an electromagnetic homeostasis, differently mental energy of frustration which breaks an electromagnetic homeostasis is produced. Destructive vibrations appear at the person as a result of action of its negative spiritual qualities or emotions: *the grief gives vibrations - from 0,1 to 2 hertz; *fear from 0,2 to 2,2 hertz; *offense from 0,6 to 3,3 hertz; *irritation - from 0,9 to 3,8 hertz; *indignation - from 0,6 to 1,9 hertz; *the egoism - gives vibrations of at most 2,8 hertz; *irascibility (irascibility) - 0,9 hertz; *rage flash - 0,5 hertz; anger - 1,4 hertz; *arrogance - 0,8 hertz; pride - 3,1 hertz; *neglect - 1,5 hertz; *superiority - 1,9 hertz; * pity - 3 hertz. Throughout the millennia the frequency of vibrations (i.e. fluctuations in a second) 
our planet made 7,8-8,2Hz. Physicists call it Schuman's frequency. It fluctuates within 8 hertz. Researchers on physical medicine noticed long ago that positive people who led a healthy lifestyle, weren't ill when the frequency of vibrations of their power field was included into a resonance with a frequency of vibrations of the planet.

The healthy condition of an organism is provided and supported by a resonance of standing electromagnetic waves of a biofield.

\section{Health of the Person}

Is a psycho-physiological state with balanced mentality and functioning of an organism at an electromagnetic frequency of cages of 8 hertz and with a wavelength of 8 meters in the resonance mode in environmentally friendly internal and environment. Electromagnetic frequency of cages of 8 hertz forms a light biofield.

\section{The Valuable Realization of Counterbalancing Mentality}

Requirements are in deep communication with outlook and the system of values. The system of values focuses the personality on this or that strategy of vital behavior. The system of values is set of estimates by the person of objects and phenomena of the world around - directly indicates how it is necessary to treat the existing requirements how it is necessary to form them and to correct. Value is assessment of the phenomena and events as I am kind or angry, useful or harmful, fine or ugly, admissible or forbidden, fair or unfair, etc. The possibility of comparison of the world around to requirements and values of the person with a brilliant accuracy is painted in an aphorism of the Ancient Greek sophist Protagor (490 - 420 BC): "The person is a measure of all things". In this statement valuable approach to the world is brightly shown. Requirements and values penetrate literally all spheres of public life, all social structures and the relations. Requirements and values act as an important link between society, the social environment and the individual, the personality, her inner world. Values represent beliefs of people about life and acceptable behavior. Moral value is acceptance on itself responsibility for the acts. Cultural wealth, love, the truth, good and beauty, are values of spiritual life of the personality. The spirituality - is internal installation of the individual to work according to the conscience.

Spiritual life of society is inconceivable without connection of spiritual production and spiritual consumption. Nobody will be able to enjoy music which isn't created! In spiritual life of society, the activity directed to creation, preservation and distribution of cultural wealth spiritual needs and spiritual consumption represents indissoluble unity.

Spiritual consumption is a special kind of activity and, therefore, it has the focus, demands certain efforts, use of appropriate means. In the course of spiritual consumption as means of achievement of the goal material resources, perform with another - the corresponding knowledge and skills, on the one hand, (to read the book, it is necessary to have an opportunity to receive it in library or to buy.) The education level and the general culture of the personality directly influences consumption of cultural wealth. Spiritual needs of the person represent internal motives to creativity, creation of cultural wealth and their development, to spiritual communication. Spiritual needs are set socially. This requirement in itself doesn't arise. It has to be created and developed by a social context, the individual's environment in difficult and long process of his education and education. At the same time at first society forms only the most elementary spiritual needs providing his socialization at the person. Spiritual needs of higher order development of richness of world culture, participation in their creation, etc. - society can form only indirectly, through the system of the cultural wealth serving as reference points in spiritual self-development of individuals. Spiritual needs have essentially unlimited character. Limits of growth of requirements of spirit don't exist. Only volumes of the spiritual riches which are already saved up by mankind, opportunities and the power of desire of the person to participate in their production can act as natural limiters of such growth. Spiritual activity is a basis of spiritual human life and society. Spiritual activity - a form of the active relation of human consciousness to the world around of which are result:

a) The new ideas, images, representations, values which are embodied in philosophical systems, scientific theories, works of art, moral, religious, legal and other views.

b) Spiritual public relations of individuals.

c) The person.

Ideal educations as a product of spiritual activity and production have the general nature of their consumption. Any spiritual value ideally can be property of all. From consumption they don't decrease as material, on the contrary, then more people seize cultural wealth, that high probability of their increment. Special type of spiritual activity is distribution of cultural wealth for the purpose of assimilation by their perhaps large number of people. The special role belongs to institutions of science, culture, church, education systems and education here. Cultural wealth the category indicating human, social and cultural value of various spiritual educations (the ideas, theories, images) considered in the context of "good and evil", "the truth or a lie" "fine or ugly", "fair or unfair". In cultural wealth the public nature of the person and a condition of his life is expressed. The person is a being spiritual, a part of the inner world created by God. The person allocated with ability to feel spiritual needs more precisely and better perceives the world around in all its variety. Such person easier and quicker understands that the behavior coinciding with moral standards except other, gives feeling of emotional satisfaction and internal tranquility, makes balanced psyche [1], transfers to a spiritual healthy lifestyle [2-15].

\section{Conclusion}

To be favorable by the spiritual person. Clever desire and a kind thought are born in the soul from love for God. Only the person allocated with a possibility of achievement of God's similarity has a balanced and perfect system of mental forces (hearts, mind, will) and their manifestations (feelings, thoughts, strong-willed acts). This magnificent system is property of human mentality. Her basic feature is the moral and spiritual orientation. Bringing up and leaning on true moral and spiritual desires of people it is capable to 
reach balanced mentality in realization of necessary material and spiritual needs.

Hygiene and endoecology, light bioenergy and natural ecology, balanced mentality and spiritual life are criterion of maintenance of a healthy state.

\section{References}

1. Vekker LM (2000) Mentality and reality: uniform theory of mental processes. M Sense, pp. 685.

2. Bryndin EG, Bryndina IE (2015) Natural-Science Aspects of Health. Weber Medicine \& Clinical Case Reports 1: 134-137.

3. Bryndin EG, Bryndina I (2015) E Spiritual processes of society and global health II Inter conf Information technologies in science, management, social sphere and medicine. TPU.

4. Bryndin EG (2012) Culture of a healthy lifestyle. Third Arkaim conf Horizons of civilization. Chelyabinsk: ChSU: 32-40.

5. Bryndin EG, Bryndina IE (2014) Management of social infrastructure of formation of a healthy lifestyle of the population. Inter symposium Society and continuous wellbeing of the person. TPU :102-106.

6. Bryndin EG, Bryndina IE (2016) Normalization of Cognitive Thinking by Healthy Lifestyle. ARC Journal of Public Health and Community Medicine 1(2): 1-6.

7. Bryndin EG, Bryndina IE (2017) Healthy Wellbeing of the Person and Society. Journal "The European Proceedings of Social \& Behavioural Sciences EpSBS 19: 130-139
8. EG Bryndin, IE Bryndina (2017) Sanatorium Rehabilitation of the Population by the Healthy Lifestyle. International journal Rehabilitation Sciences 2(2): 35-40.

9. EG Bryndin, IE Bryndina (2017) Formation of Public Health Care on Basis of Healthy Lifestyle. International Journal of Psychological and Brain Sciences 2(3): 63-68.

10. Bryndin EG, Bryndina IE (2017) Natural Measures of Normalization of Vital Systems of the Person for Maintaining of the Healthy State. Journal of Health Research. 1: 25-38.

11. Bryndin EG, Bryndina IE (2018) Natural Technology of High-Quality Transition to Healthy Activity. J Galore International Journal of Health Sciences and Research 3(1): 24-32.

12. Bryndin EG (2018) Psychological and Social Aspects Formations of Thinking, Consciousness and Behavior. SM Physical Medicine \& Rehabilitation 2(1): 1-5.

13. Evgeniy Bryndin, Irina Bryndina (2018) Natural and Spiritual Aspects of Health and Social Infrastructure of Public Health Care on Base of Healthy Lifestyle. Medical Open Journal Gerontology \& Geriatrics. 3(6): 404-408.

14. Evgeniy Bryndin (2018) Satisfaction with valuable realization of requirements by spiritual personality counterbalances psyche. MOJ Public Health 7(6): 254-257.

15. Evgeniy Bryndin, Irina Bryndina (2019) International Public Health Care on Basis Healthy Lifestyle. Asian Journal of Medical Science Research \& Review 1(2): 88-96.

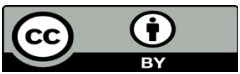

This work is licensed under Creative Commons Attribution 4.0 License

To Submit Your Article Click Here:

Submit Article

DOI: $10.32474 /$ RRHOAJ.2019.04.000177

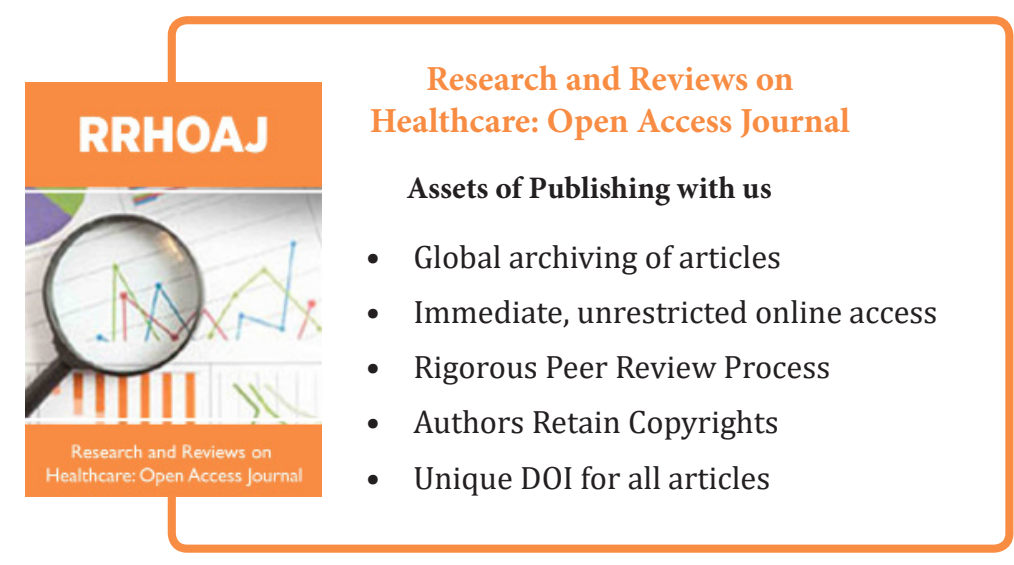

